\title{
Factors affecting success of an integrated community-based telehealth system
}

\author{
Hui-Lung Hsieh ${ }^{\mathrm{a}}$, Chung-Hung Tsai ${ }^{\mathrm{b}, *}$, Wen-Hai Chih ${ }^{\mathrm{c}}$ and Huei-Hsieh Lin ${ }^{\mathrm{d}}$ \\ ${ }^{a}$ Chu Shang Show Chwan Hospital, Nantou, Taiwan \\ ${ }^{\mathrm{b}}$ Department of Health Administration, Tzu Chi College of Technology, Hualien, Taiwan \\ ${ }^{\mathrm{c}}$ Department of Business Administration, National Dong Hwa University, Hualien, Taiwan \\ ${ }^{\mathrm{d}}$ Department of Finance and Taxation, Takming University of Science and Technology, Taipei, Taiwan
}

\begin{abstract}
.
BACKGROUND: The rise of chronic and degenerative diseases in developed countries has become one critical epidemiologic issue. Telehealth can provide one viable way to enhance health care, public health, and health education delivery and support. OBJECTIVE: The study aims to empirically examine and evaluate the success factors of community-based telehealth system adoption.

METHODS: The valid 336 respondents are the residents of a rural community in Taiwan. The structural equation modeling (SEM) was used to assess the proposed model applied to telehealth.

RESULTS: The findings showed the research model had good explanatory power and fitness. Also, the findings indicated that system quality exerted the strongest overall effect on intention to use. Furthermore, service quality exerted the strongest overall effect on user satisfaction. The findings also illustrated that the joint effects of three intrinsic qualities (system quality, information quality, and service quality) on use were mediated by user satisfaction and intention to use.

CONCLUSION: The study implies that community-based telehealth service providers should improve three intrinsic qualities to enhance user satisfaction and intention to use, which in turn can lead to increase the usage of the telehealth equipment. The integrated community-based telehealth system may become an innovative and suitable way to deliver better care to the residents of communities.
\end{abstract}

Keywords: Information success model, integrated community-based telehealth

\section{Introduction}

The rise in the phenomenon of the aging of the population in the world has led to some crucial issues about elderly health be emerging. Recently, the rise of chronic and degenerative diseases in developed countries has become one critical epidemiologic issue. Also, population aging will influence patterns of health care in future. The institutional long-term care services are widely available in developed countries. Both the use of medical care services and health care expenditures are relatively higher in older populations [1]. With demands on health care providers to improve quality, efficiency, and cost-effectiveness, identifying the appropriate use of technology for different patient populations in the provision of health services is critical. Telehealth is one kind of technology to improve management of chronic illness and long-term care services [2].

\footnotetext{
${ }^{*}$ Corresponding author: Chung-Hung Tsai, Department of Health Administration, Tzu Chi College of Technology, Hualien, Taiwan.E-mail: tsairob@tccn.edu.tw.

0928-7329/15/\$35.00 (C) 2015 - IOS Press and the authors. All rights reserved

This article is published online with Open Access and distributed under the terms of the Creative Commons Attribution NonCommercial License.
} 
Using telecommunications technologies, telehealth can provide one viable way to enhance health care, public health, and health education delivery and support [3]. Telehealth is now broadly used as it describes the wide range of diagnosis and management, education, and other related fields of health care [4]. Recently, many health institutions are incorporating telehealth into their care services, and implementation has ranged from small scale pilot programs through to large scale changes in service delivery [3].

A literature review by DeLone and McLean in the field of management information systems aimed at identifying determinants for system success. They presented a framework with six dimensions of success, that is, system quality, information quality, service quality, user satisfaction, usage, and net benefits [5]. Since DeLone and McLean (D\&M) developed their model of IS success, there has been much research on the topic of success as well as extensions and tests of their model [6]. Recently, several studies have also applied D\&M IS Success Model to evaluate information technology in health care context (e.g., [7]). However, it has seldom been used to explain the success of telehealth, which represents both emerging information technology and health delivery service. Thus, it is necessary to employ this model to examine the crucial success factors of telehealth.

\section{Literature review}

\subsection{Integrated community-based telehealth}

Telehealth refers to a range of technologies that bridge geographic distances in health care delivery, by enabling patients to virtually visit providers, conduct remote monitoring of health status or receive disease-specific information [8]. Telehealth involves people monitoring their own vital signs, such as blood pressure or blood sugar, using a machine in the home, with results monitored remotely by health professionals. If results give cause for concern, the individual can be contacted and advised, or visited if necessary, by a nurse or doctor [9]. Telehealth technology has the potential to increase quality to healthcare and to lower costs [10].

Several telehealth systems have been developed and evaluated for use by elders in their homes, that is, home-based telehealth model. Home-based telehealth can enhance older adults' access to care and facilitate patient-provider collaboration, which in turn may improve patient self management. An alternative model for community dwelling older adults is integrated community-based telehealth model, which is the use of telehealth technology in community settings (such as community centers, neighborhood clinics, libraries) that can be used in multiple users [11]. Courtney et al. [8] argued that community-based telehealth may be a useful strategy to address health disparities and the digital divide by bringing telehealth services to underserved individuals who have limited access because of cost, experience, and training.

In general, there are two main kinds of processes in integrated community-based telehealth: real-time (i.e. synchronous system) and store-and-forward (i.e. asynchronous system). Telehealth services can be delivery effectively via these two processes [12]. The synchronous services can help physician online visit the patients in real time. Alternately, asynchronous services are to save patients' electronic medical records (EMR) on a client site and then sent thee information to a physician or call center located at remote areas. In synchronous systems, videoconferencing provides a patient and health care provider at either end with interactive clinical encounter via a live telecommunication linkage. Some studies have demonstrated that videoconferencing was a viable method for facilitating cancer support groups to rural communities [13]. On the other hand, asynchronous systems involve the collection and electronic storage 


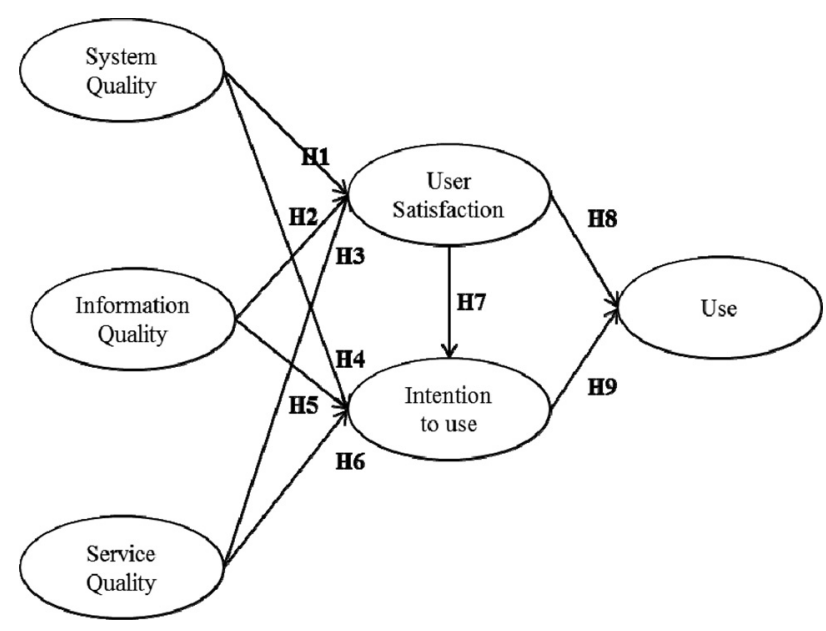

Fig. 1. The proposed integrated community-based telehealth success model.

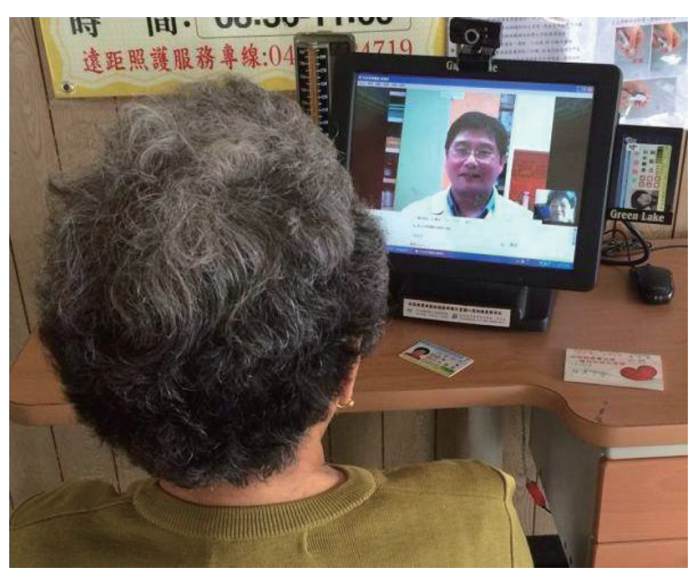

Fig. 2. The synchronous system.

of personal health record (PHR; e.g. vital signs) captured in one location and forwarded elsewhere for interpretation and evaluation. Both two kinds of telehealth services allow health care providers to assess, diagnose, and treat patients without requiring the patient and the provider to be in the same location [14].

\subsection{D\&M IS Success Model}

D\&M Information System Success Model (D\&M IS Success Model) is a framework to conceptualize and operationalize information system success. DeLone and McLean proposed that there are six categories of IS success measures, that is system quality, information quality, use/intention to use, user satisfaction, individual impact, and organizational Impact. Service quality was included later in their model [15[16]. D\&M IS Success Model argued that three intrinsic qualities (system quality, information system, and service quality) jointly affect user satisfaction and users' intention to use, further impacting net benefits.

System quality refers to an information system's attributes or characteristics. It includes features such as flexibility, stability, credibility, usefulness, usability, ease of use, and accessibility. Information quality is an information system's input and output quality, including mainly information accuracy, fitness of information for user, credibility, correlation, completeness, accuracy, timeliness, and brevity [17]. Service quality related to the information department or personnel support quality. including the punctual, professional, and personalized service provided by the service provider [18]. Brownsell [19] argued that care providers' engagement is one of prerequisites for telehealth success. Thus, care providers' support was also integrated into service quality measurement in this study, including professional and empathic attitude toward residents.

Use refers to the extent to which users adopt an information system, such as number of entries, usage frequency, users' number, usage time, etc. Intention to use is a kind of attitude while use is a behavior. According to According to Davis et al. [20], intention to use an information system will affect usage behavior. User satisfaction refers to the degree to which users satisfy with an information system, which is also an important construct for measuring customers' view of the system. These metrics include repeated purchase and repeated use of the web site. Net benefits refer to the effects of an information system on individual or organizational performance. The following metrics are the main ones for measuring net 


\begin{tabular}{lccc}
\multicolumn{5}{c}{ Table 1 } \\
\multicolumn{4}{c}{ Cronbach's $\alpha$, CR and AVE values } \\
\hline Construct & Cronbach's $\alpha$ & CR & AVE \\
\hline System quality & 0.803 & 0.815 & 0.599 \\
Information quality & 0.988 & 0.988 & 0.964 \\
Service quality & 0.977 & 0.977 & 0.935 \\
User satisfaction & 0.722 & 0.745 & 0.504 \\
Intention to use & 0.965 & 0.860 & 0.754 \\
Use & 0.934 & 0.937 & 0.834 \\
\hline
\end{tabular}

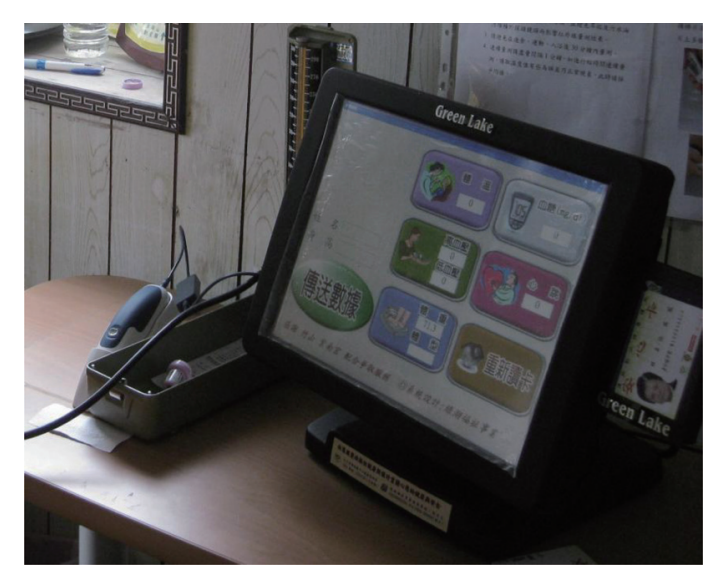

Fig. 3. The asynchronous system.

benefits in e-commerce context: cost saving, market expansion, sales increase, search cost reduction, and time savings.

The D\&M IS success model has received much attention in IS field and a number of studies have undertaken empirical investigations to examine the measurement and multidimensional relationships of IS success. The D\&M IS success model has also been applied in some studies of health information systems [21|22]. However, it has seldom been used to explain the success of telehealth. Accordingly, we employed the model to evaluate success in integrated community-based telehealth, illustrated in Fig. 1.

\section{Method}

\subsection{The integrated community-based telehealth}

The target integrated community-based telehealth system includes real-time videoconferencing (the synchronous system is shown in Fig. 2) and store-and-forward system (the asynchronous system is shown in Fig. 3). The main devices of synchronous system include camera, TV/computer monitor, commercial cable modem and network, which integrate into a two-way video and audio transmission system. Videoconferencing not only gives the residents the means to contact professional staffs but also allows clinicians to assess the residents' health status.

There are several peripherals accompanied the asynchronous system. The whole equipment measures residents' physiological health status. It includes body weight, blood pressure, blood sugar, heart rate, and blood oxygen.

\subsection{Data collection}

We used a structured questionnaire to collect research data in this study. The research model includes six factors. Each factor was measured with multiple items. All measurement items were adapted from previous literature to improve content validity. All items were measured using a five-point scale ranging from 1 (strongly disagree) to 5 (strongly agree). These question items were adapted from DeLone and McLean [15|16], Sicotte et al. [21] and Trudel et al. [22]. 
Table 2

Squared correlation of factors and AVE values

\begin{tabular}{lllllll}
\hline & \multicolumn{1}{c}{1} & 2 & 3 & 4 & 5 & 6 \\
\hline 1. System quality & $(0.774)$ & & & & & \\
2. Information quality & $0.399^{* * *}$ & $(0.982)$ & & & & \\
3. Service quality & $0.293^{* * *}$ & $0.212^{* * *}$ & $(0.967)$ & & & \\
4. User satisfaction & $0.526^{* * *}$ & $0.523^{* * *}$ & $0.552^{* * *}$ & $(0.710)$ & & \\
5. Intention to use & $0.424^{* * *}$ & $0.329 * * *$ & $0.346^{* * *}$ & $0.463 * * *$ & $(0.869)$ & \\
6. Use & $0.424 * * *$ & $0.302^{* * *}$ & $0.300^{* * *}$ & $0.438^{* * *}$ & $0.772 * * *$ & $(0.913)$ \\
\hline
\end{tabular}

Table 3

Actual and recommended fit indices values

\begin{tabular}{lrrrrrrr}
\hline Fit indices & $\chi^{2} /$ d.f. & GFI & AGFI & RMSEA & RMR & CFI & NFI \\
\hline Actual values & 4.142 & 0.874 & 0.820 & 0.097 & 0.020 & 0.950 & 0.935 \\
Recommended values & $<5$ & $>0.90$ & $>0.80$ & $<0.05$ & $<0.05$ & $>0.90$ & $>0.90$ \\
\hline
\end{tabular}

\section{Results}

\subsection{Descriptive statistics}

There were 336 valid responses in this study. Of the 336 valid responses, 56.0 percent was women (188) and 44.0 percent was men (148). In terms of age, 70.2 percent was aged 71-80 years, 17.0 percent was aged $61-70,8.0$ percent was aged 51-60, 1.8 percent was aged $41-50$, and 3.0 percent was under 40 years old. In terms of education level, most participants had elementary school degree (44.6\%). The majority of residents' caregivers were married (39.9\%). According to descriptive statistics analysis, the participants' perceptions of all the six constructs in this study were positive (the mean values ranged from 4.35 to 4.78$)$.

\subsection{Measurement model and structural model}

We used structural equation modeling (SEM) to examine the model and hypotheses proposed in this study. The data analysis was conducted in accordance with a two-step approach [23]. Firstly, the measurement model was developed to validate reliability and validity by confirmatory factor analysis. Secondly, the structural model was conducted to examine hypotheses testing and goodness-of-fit indices of the proposed model.

Cronbach's $\alpha$ tests determines the internal consistency of items in a survey instrument. As shown in Table 1, Cronbach's $\alpha$ of all the six constructs exceeded the suggested acceptability value 0.7 [24]. In addition, the composite reliability (CR) values, which ranged from 0.75 to 0.99 , and the average variances extracted (AVE) values, which ranged from 0.50 to 0.96 . All CRs exceed 0.7 and all AVEs exceed 0.5. Therefore, the findings showed convergent validities of all constructs were well [25].

As listed in Table 2, the squared correlation and AVE matrix, with the squared correlations among constructs and the AVE on the diagonal. The AVE value of each construct was significantly larger than its squared correlation with other constructs, showing good discriminant validity [26].

Subsequently, we used AMOS 18.0 statistical software to validate the proposed structural model. The recommended and actual values fit indices are listed in Table 3. Except for GFI and RMSEA were slightly worse than the recommended value, these other fit statistics of $\chi^{2} /$ d.f., AGFI, RMR, CFI and NFI were far better than the recommended value. Thus, these goodness-of-fit indices revealed that the structural model generally fitted well for the sample data. 
Table 4

Standardized overall effects

\begin{tabular}{lccc}
\hline Construct & $\begin{array}{c}\text { User } \\
\text { satisfaction }\end{array}$ & $\begin{array}{c}\text { Intention } \\
\text { to use }\end{array}$ & Use \\
\hline System quality & 0.402 & 0.370 & 0.326 \\
Information quality & 0.359 & 0.090 & 0.117 \\
Service quality & 0.413 & 0.196 & 0.201 \\
User satisfaction & - & 0.324 & 0.379 \\
Intention to use & - & - & 0.724 \\
Use & - & - & - \\
\hline
\end{tabular}

\subsection{Hypotheses testing}

Figure 4 indicates the hypotheses testing results of structural model. It includes standardized path coefficients, path significance, and $R^{2}$. System quality $(\beta=0.402)$, information quality $(\beta=0.359)$, and service quality $(\beta=0.413)$ were found to significantly and positively affect user satisfaction, accounting for $76.6 \%$ of the variance in user satisfaction. Therefore, $\mathrm{H} 1, \mathrm{H} 2$, and $\mathrm{H} 3$ were supported. System quality $(\beta=0.240)$ and user satisfaction $(\beta=0.324)$ were found to have significantly and positively affect intention to use, accounting for $29.4 \%$ of the variance in intention to use. Thus, H4 and H7 were supported. However, information quality and service quality didn't affect intention to use significantly, implying that $\mathrm{H} 5$ and $\mathrm{H} 6$ were not supported. User satisfaction $(\beta=0.144)$ and Intention to use $(\beta=$ 0.724 ) were found to significantly and positively affect use, accounting for $65.3 \%$ of the variance in use. Thus, $\mathrm{H} 8$ and $\mathrm{H} 9$ are supported.

The findings in Table 4 listed the standardized overall effects in the proposed model. As shown in Table 4, in terms of overall effect, intention to use is the strongest factor among antecedents of use. System quality is the strongest factor among antecedents of intention to use. In addition, system quality is also the strongest factor among antecedents of user satisfaction.

\section{Conclusions}

This study empirically examined and evaluated the success factors of a rural community's residents in using integrated community-based telehealth. The results of this study indicated that all average scores for these six constructs were very high: the scores were from 4.29 (system quality) to 4.78 (service quality) out of 5. Overall, the participants very satisfied with the integrated community-based telehealth facilities of this rural township. These results were consistent with that presented in Doorenbos et al. [13]. The findings suggested that integrated community-based telehealth has been seen as a viable way to facilitate residents to access care and support services in rural communities.

This study also investigated the determinants of success of the integrated community-based telehealth toward elderly rural residents in Taiwan. The results of SEM showed that almost all hypotheses were 
supported. These results were consistent with that presented in Sicotte et al. [21]. However, both information quality and service quality didn't affect intention to use significantly. The possible reason may be that the two intrinsic qualities don't directly affect the intention to use system. Instead, the effects of both information quality and service quality on intention to use may be mediated by user satisfaction. Accordingly, once the residents satisfy with these accompanied benefits, they will tend to use the system. These above discussions confirm the need for further research on how perceived information and service quality affect intended system use, with the mediation of user satisfaction.

Moreover, system quality had the strongest overall effect on intention to use. The evidence implies that high level of system quality is necessary for prompting engagement in adoptive behaviors towards the community-based telehealth system. Examples of high level of system quality include ease of use, high transmission speed, high screen revolution, robust cable or computer network, and low reading failure rate.

In addition, service quality exerted the strongest overall effect on user satisfaction. Thus, health care providers (such as physicians, nurses, and professional staffs) play very important role during an online visit, because they can provide residents with pertinent information and assistance in real time to better manage their own health. The nutritional and pharmaceutical services should also be incorporated into care delivery process of telehealth to improve residents' physical and mental health. Besides, both remote call centers and IT department should cooperate to provide residents with real-time, reliable, and empathic support when these elderly feel anxiety about adoption process.

Findings from this study suggest that integrated community-based telehealth may be a useful strategy to address health inequalities and improve medical accessibility by integrating telehealth services to underserved communities. This study highlighted the importance of the perceived intrinsic qualities and attitudes towards integrated community telehealth systems that promote holistic healthcare of community residents. We hope this study to become a milestone for future research with regard to integrated community-based telehealth.

\section{References}

[1] WHO. Global Health and Aging, Retrieved from http://www. who. int/ageing/publications/by_title/en/. 2011.

[2] Dansky KH, Vasey J, Bowles K. Use of telehealth by older adults to manage heart failure. Research in Gerontological Nursing. 2008; 1(1): 25-32.

[3] Wade R, Shaw K, Cartwright C. Factors affecting provision of successful monitoring in home telehealth. Gerontology. 2012; 58(4): 371-377.

[4] Center for Connected Health Policy, What is telehealth, Retrieved from http://cchpca.org/what-is-telehealth, 2014.

[5] van der Meijden MJ, Tange HJ, Troost J, Hasman A. Determinants of success of inpatient clinical information systems: A literature review. Journal of the American Medical Informatics Association. 2003; 10(3): 235-243.

[6] Petter S, DeLone W, McLean E. Measuring information systems success: models, dimensions, measures, and interrelationships. European Journal of Information Systems. 2008; 17: 236-263.

[7] Tannery NH, Barbara A, Epstein MSLS, Charles B, Wessel MLS, Yarger F, LaDue J, Klem ML. Impact and user satisfaction of a clinical information portal embedded in an electronic health record. Perspectives in Health Information Management. 2011; 8: 1-10.

[8] Courtney KL, Lingler JH, Mecca LP, Garlock LA, Schulz R, Dick AW, Olshansky E. Older adults' and case managers' initial impressions of community-based telehealth kiosks. Research in Gerontological Nursing. 2010; 3(4): 235-239.

[9] Cook R. Introducing: Telehealth and telecare. British Journal of Community Nursing. 2007; 12(7): 307-307.

[10] Gagnon MP, Lamothe L, Fortin JP, Cloutier A, Godin G, Gagné C, Reinharz D. Telehealth adoption in hospitals: An organisational perspective. Journal of Health Organization and Management. 2005; 19(1): 32-56.

[11] Demiris G, Thompson H, Boquet J, Le T, Chaudhuri S, Chung J. Older adults' acceptance of a community-based telehealth wellness system. Informatics for Health and Social Care. 2013; 38(1): 27-36.

[12] Lancaster P, Krumm M, Ribera J, Klich R. Remote Hearing Screenings via Telehealth in a Rural Elementary School. American Journal of Audiology. 2008; 17(2):114-22. 
[13] Doorenbos AZ, Eaton LH, Haozous E, Towle C, Revels L, Buchwald D. Satisfaction with telehealth for cancer support groups in rural american indian and alaska native communities. Clinical Journal of Oncology Nursing. 2010; 14(6): 765-770.

[14] California Healthcare Foundation. Chronicling an entry into telehealth: Open Door Community Health Centers. 2010.

[15] DeLone WH, McLean ER. Information systems success: The quest for the dependent variable. Information System Research. 1992; 3(1): 60-95.

[16] DeLone WH, McLean ER. The DeLone and McLean model of information systems success: A ten year update. Journal of Management Information Systems. 2003; 19(4): 9-30.

[17] Rai A, Lang SS, Welker RB. Assessing the validity of IS success models: An empirical test and theoretical analysis. Information Systems Research. 2002; 13(1): 50-69.

[18] Chou CH. Using DeLone and McLean model to analyze determinants of portal sites success. Journal of Information Management. 2006; 8(1): 109-132.

[19] Brownsell S. Measuring the 'success' of telehealth interventions. Journal of Assistive Technologies. 2009; 3(4): 12-20.

[20] Davis FD, Bagozzi RP, Warshaw PR. User acceptance of computer technology: A comparison of two theoretical models. Management Science. 1989; 35(8): 982-1002.

[21] Sicotte C, Paré G, Bini KK, Moreault MP, Laverdure G. Virtual organization of hospital medical imaging: A user satisfaction survey. Journal of Digit Imaging. 2010; 23(6): 689-700.

[22] Trudel MC, Paré G, Têtu B, Sicotte C. The effects of a regional telepathology project: A study protocol. BMC Health Services Research. 2012; 12(64).

[23] Anderson JC, Gerbing, DW. Structural equation modeling in practice: A review and recommended two-step approach. Psychological Bulletin. 1988; 103: 411-423.

[24] Nunnally JC. Psychometric Theory. 2nd ed. New York: McGraw-Hill; 1978.

[25] Gefen D, Straub DW, Boudreau MC. Structural equation modeling and regression: Guidelines for research practice. Communications of Association for Information Systems. 2000; 4(7): 1-70.

[26] Fornell C, Larcker DF. Evaluating structural equation models with unobservable variables and measurement error. Journal of Marketing Research. 1981; 18: 39-50. 